\title{
Vascular failure and recent anti-diabetic drugs
}

\author{
Jun-ichi Oyama, $\mathrm{MD}, \mathrm{PhD}^{1)}$ and Koichi Node, $\mathrm{MD}, \mathrm{PhD}^{2)}$
}

\begin{abstract}
:
Type 2 diabetes mellitus (T2DM) is highly prevalent and is a critical risk factor for cardiovascular (CV) disease, increasing both morbidity and mortality. T2DM is one of the most important classical CV risk factors that promote atherosclerosis. Therefore, it is important for both patients with T2DM and their doctors to identify vascular dysfunction at an early stage of atherosclerosis. Recently, new therapies based on the actions of the incretin hormones and blockade of sodium glucose transporter (SGLT) 2 have become widely used, because they offer advantages over conventional treatments by achieving glycemic control and/or possible reducing CV risks. Many experimental studies have suggested that glucagon-like peptide (GLP)-1 and dipeptidyl peptidase (DPP)-4 inhibitors exert cardioprotective effects on atherosclerosis and cardiac dysfunction both in vitro and in vivo. However, thus far, there is little clinical evidence supporting the efficacy of incretin therapy in patients with CV disease. In contrast, the SGLT2 inhibitor empagliflozin achieved a remarkable reduction in CV-related mortality in a large clinical study. The present review focuses on the effects of GLP-1-related therapies and SGLT2 inhibitors on clinical indices of endothelial function.
\end{abstract}

\section{Key words:}

Vascular failure, Endothelial function, GLP-1, DPP-4 inhibitor, SGLT2 inhibitor

\section{Introduction}

Type 2 diabetes mellitus (T2DM) is one of the most important risk factors for the development of cardiovascular (CV) disease, because it promotes both systemic atherosclerosis and lifestyle-associated diseases. Cardiovascular complications are an important cause of morbidity and mortality in patients with diabetes, and endothelial dysfunction is an early indicator of developing cardiovascular complications.

Recently, several new classes of antidiabetic drugs, including glucagon-like peptide (GLP)-1, dipeptidyl peptidase (DPP)-4 inhibitors, and sodium glucose cotransporter 2 (SGLT2) inhibitors, which have different mechanisms of action from those of conventional antidiabetic agents, have become widely used. In this article, we review the effects of these agents, with a focus on the significance of endothelial function.

\section{Endothelial function}

\subsection{Regulation of the vascular system}

Blood vessels are composed of three layers of tissue and modulate vascular tone and blood flow by constricting or relaxing in response to physical, neurological, and chemical stimuli. The endothelium is a flat monolayer of cells that covers vascular lumina and plays a role as a barrier between blood and the vessel wall, preventing the aggregation of platelets and invasion of macrophages.

Vasodilator molecules are released in response to shear stress. Vascular endothelial cells can produce and secrete several vasodilators, including nitric oxide (NO), prostaglandin $\mathrm{I}_{2}, \mathrm{C}$-type natriuretic peptide, and endotheliumderived hyperpolarizing factor (EDHF). The cells also produce several vasoconstrictors, including endothelin, angiotensin II, prostaglandin $\mathrm{H}_{2}$, and thromboxane $\mathrm{A}_{2}$. $\mathrm{NO}$ in particular plays a significant role in atherorsclerosis ${ }^{1)}$. Normally, endothelial NO synthase (eNOS) is activated by shear stress caused by blood flow and various agonists that stimu-

1) Department of Circulatory Regulation in Medicine, Saga University, Saga, Japan

2) Department of Cardiovascular Medicine, Saga University, Saga, Japan

Corresponding author: Jun-ichi Oyama, MD, PhD, junoyama@cc.saga-u.ac.jp

Received: February 17, 2017, Accepted: March 29, 2017

Copyright (C) 2017 Japan Society for Vascular Failure 
Table 1. Endothelial function

\begin{tabular}{lcccc}
\hline \multicolumn{1}{c}{ Position } & Method & Stimulus & Advantage & Disadvantage \\
\hline $\begin{array}{l}\text { Brachial artery } \\
\text { Brachial artery }\end{array}$ & SPG & ACh & High specificity & Invasive \\
FMD & Reactive hyperemia & $\begin{array}{c}\text { Non-invasive } \\
\text { Simple }\end{array}$ & Low specificity \\
Finger & RH-PAT & Reactive hyperemia & Non-invasive & Low specificity \\
Coronary artery & Flow-wire & ACh & High specificity & Invasive \\
Blood/Urine & Bioactive substance & None & Simple & Complicated \\
& & & & Sery low specificity \\
\end{tabular}

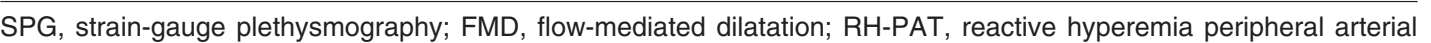
tonometry; ACh, acetylcholine

late mechanically or bind with receptors on vascular endothelial cells. NO can be produced from L-arginine, and when released, it is transferred to vascular smooth muscle cells in the immediate vicinity by diffusion. It then activates soluble guanylate cyclase in the cell, relaxes vascular smooth muscle, and inhibits chemotaxis and platelet aggregation by increasing the amount of cyclic guanosine 3',5'monophosphate (cGMP) $)^{1-3)}$.

Thus, normal vascular endothelium functions to regulate and maintain vascular homeostasis through multiple and complex physiological functions, including the release of vasoactive factors that regulate vascular tone, blood fluidity, and coagulation, while limiting vascular smooth muscle cell proliferation and inflammation ${ }^{3-5)}$.

\subsection{The concept of vascular failure}

Clinically, abnormalities of vascular endothelium are critical in relation to atherosclerosis, hypertension, and diabetes. Oxidative stress, inflammation, obesity, hyperlipidemia, and insulin resistance are major contributors to endothelial dysfunction in cardiovascular disorders. Endothelial dysfunction is strongly associated with aging, atherosclerosis, diabetes, hyperlipidemia, hypertension, and obesity ${ }^{6}$.

Imbalances in the production of endothelium-derived relaxing and contracting factors are important contributors to endothelial dysfunction ${ }^{1)}$. Decreased synthesis and/or increased degradation of $\mathrm{NO}$ can contribute to impairment of its bioavailability as a consequence of enhanced production of reactive oxygen species $(\mathrm{ROS})^{7,8)}$.

Tetrahydrobioptein (BH4) binds to NOS as a cofactor and suppresses superoxide production". However, insufficient $\mathrm{BH} 4$ directs NOS to produce superoxide rather than $\mathrm{NO}^{10)}$, and increased oxidative stress can oxidize $\mathrm{BH} 4$, resulting in the uncoupling of eNOS and reduced NO production ${ }^{11,12}$. Moreover, the absence of $\mathrm{BH} 4$ increases oxidative stress through transfer of electrons to molecular oxygen, forming oxidant species that further consume NO and increase oxidative stress $^{7,11,12}$. Given that superoxide converts NO into peroxynitrite, generates hydroxyl radicals, and injures cells, the balance of production and the existence of NO, superoxide, and related factors in vascular endothelial cells play important roles in vascular endothelial injury.
Elevated levels of asymmetric dimethylarginine (ADMA) may reduce NO production, because ADMA is an endogenous inhibitor of eNOS through competition with Larginine $^{7}$. Endothelial dysfunction can affect vasoconstrictor levels, including endothelin-1 and angiotensin II, and other vasodilators, including endothelial-derived hyperpolarizing factor $(\mathrm{EDHF})$ and prostacyclinn ${ }^{7,8)}$. Therefore, increased ROS, inflammatory, and vasomotor factors and deficiency of NO bioavailability are hallmarks of endothelial dysfunction $^{13)}$. Dysfunctional endothelial cells may permit increases in leukocyte adhesion, permeability, inflammatory cell infiltration, and lipid deposition, thereby aggravating atherosclerotic plaque formation ${ }^{14,15}$. In addition, the proliferation, migration, and apoptosis of endothelial cells are closely related to endothelial dysfunction in cardiovascular disorders ${ }^{16,17}$. Because atherosclerosis is characterized as a response to chronic multifactorial injury and inflammation, which leads to the formation of atheromatous or fibrous plaques, vascular endothelial dysfunction occurs in the early stages of the disease and is closely related to it mechanistically.

In addition to endothelial dysfunction, smooth muscle dysfunction, metabolic abnormalities of the vessel wall including inflammation, oxidative stress, and neurohormonal imbalance occur at various stages of atherosclerosis. The concept of "vascular failure" is defined as the integration of these vascular abnormalities ${ }^{18)}$. Vascular failure is not an anatomical disease but a syndrome of abnormal vascular function beyond endothelial dysfunction, because the vasculature is not merely a system of conduits, but an endocrine organ that regulates the total blood supply to end-organs by contracting and relaxing. Vascular failure encompasses several divergent concepts from risk factors to established atherosclerotic disease with arterial stenosis, and further to calcification of the vessel wall or serious vascular events including plaque rupture and thrombo-embolic occlusion. Therefore, active intervention to correct risk factors is important to treat the condition. Comprehension and therapeutic strategies against vascular failure may be expected to prevent and treat vascular lesions. 


\subsection{Measurement of endothelial function and its clinical utility}

Table 1 lists the methods available for evaluating endothelial function. Indirect measures in the peripheral circulation assess the vasodilatory responses of conduit and resistance arteries to stimuli that increase NO release ${ }^{2,7}$. Endothelial function can be assessed by invasive and non-invasive methods. Invasive angiographic quantification of the changes in vascular diameter in response to intra-coronary infusion of muscarinic receptor agonists such as acetylcholine (ACh) is used to evaluate endothelium-dependent vasodilation ${ }^{19}$. In contrast, endothelium-independent relaxation is measured using an NO donor such as sodium nitroprusside or nitroglycerin, because NO directly acts on vascular smooth muscle cells. Invasive venous occlusion strain-gauge plethysmography (SPG) can be used to evaluate blood flow changes in the forearm circulation following hyperemia or after intraarterial infusion of $\mathrm{ACh}^{20,21}$. However, invasive methods are technically difficult and cannot be used routinely.

Thereafter, flow-mediated dilatation (FMD) is measured in the brachial artery, using high-resolution ultrasonography as a non-invasive measure of endothelium-dependent function $^{22,23)}$. FMD quantifies the transient changes that occur in the diameter of the brachial artery in response to shear stress generated by hyperemia following an induced period of local ischemia. FMD is calculated as the percentage change in brachial artery diameter from baseline in response to the increase in blood flow. Non-invasive ultrasound FMD of the brachial artery is now widely used, although results vary owing to technical issues, and the procedure is not easy to standardize among institutions.

For the assessment of pre-clinical disease, procedures for measuring endothelial function that are simple, non-invasive, reliable, reproducible, and inexpensive are desirable. Recently, reactive hyperemia peripheral arterial tonometry (RHPAT) has become commercially available to evaluate endothelial dysfunction ${ }^{24,25}$. It is an automated, quantitative, noninvasive, clinical procedure for the digital measurement of hyperemic responsiveness to assess peripheral vasodilator function. RH-PAT correlates positively with FMD and inversely with various cardiovascular risk factors and has been shown to have good reproducibility ${ }^{26,27}$.

\subsection{Predictive value of endothelial dysfunction}

Endothelial dysfunction not only represents the present status of vascular function but also acts as an independent predictor of future cardiovascular events ${ }^{28,29}$. Endothelial dysfunction is thought to be reversible and useful as a screening test for pre-arteriosclerosis changes in the vessel wall. Risk of future cardiovascular disease can be assessed by screening for endothelial dysfunction, enabling early intervention to prevent the development of complications. As therapeutic interventions, drug and supplemental therapy, and modifications of lifestyle habits are available, treatment of vascular endothelial dysfunction is of potential value in the primary prevention of atherosclerosis. Therefore, it is important to undertake intensive screening for endothelial dysfunction in the early stages of arteriosclerosis.

\section{Diabetes and endothelial dysfunction}

\subsection{Incretin-related agents on endothelial function}

\section{In vitro experiments}

Several studies in vitro have found that GLP-1 attenuated tumor necrosis factor-alpha (TNF- $\alpha$ )-mediated induction of plasminogen activator inhibitor-1 expression, advanced glycation end-product (AGE)-induced upregulation of vascular cell adhesion molecule (VCAM)-1, and ROS-induced protein kinase A activation-mediated cell senescence all upregulate the expression of eNOS in human umbilical vein endothelial cells (HUVEC ${ }^{30-33}$. In cardiac microvascular endothelial cells, glycotoxicity-induced ROS production and apoptosis were decreased by GLP-1 with an increase in cAMP/ PKA activity ${ }^{34)}$. On the other hand, GLP-1 promoted angiogenesis in a dose-dependent manner and restored oxidized LDL-induced loss of cell viability accompanied by a decrease in intracellular NO activity ${ }^{35,36}$. GLP-1 also improved the proliferation and differentiation of endothelial progenitor cells by increasing vascular endothelial growth factor (VEGF) generation ${ }^{37}$. The proliferation of human coronary artery endothelial cells was promoted by exendin-4, a GLP$1 \mathrm{R}$ agonist, through eNOS-, PKA- and PI3K/Akt-dependent pathways via the GLP-1 receptor ${ }^{38}$. Exendin-4 also restored eNOS-induced ROS production due to lipotoxicity and protected against lipoapoptosis ${ }^{39}$. Liraglutide, a GLP-1 analogue, prevented the onset of glycotoxity-induced endoplasmic reticulum stress in HUVEC, inhibited TNF- $\alpha$-induced intracellular adhesion molecule (ICAM)-1 and VCAM-1 expression via GLP-1R, attenuated ROS production, and increased the expression of anti-oxidant enzymes in HU$\mathrm{VEC}^{40-42)}$.

Because DPP-4 inhibitors act by inhibiting the degradation of GLP-1, thereby maintaining the plasma level of active GLP-1, sitagliptin augments the protective effects of GLP-1 on the eNOS mRNA level in AGEs-exposed HUVEC while suppressing the receptor for AGE expression and subsequent ROS generation ${ }^{43}$. Alogliptin-induced vascular relaxation via NO and EDHF-mediated mechanisms, as well as increased NO production with eNOS phosphorylation in HUVEC, may be mediated by GLP-1R-independent mechanisms $^{44}$.

\section{In vivo or ex vivo experiments}

Exendin-4 increased NO production, improved endothelium-dependent vasodilation, and reduced the expression of NF- $\mathrm{KB}$ via the cAMP or AMPK-eNOS pathways in aortas isolated from obese rats ${ }^{45}$. Exendin- 4 also inhibited monocyte adhesion and attenuated the formation of atherosclerotic lesions in apolipoprotein E-deficient $\left(\mathrm{ApoE}^{-{ }^{-}}\right)$ mice ${ }^{46}$. Liraglutide improved endothelial function via GLP- 
Table 2. Characteristics of studies included in this review

\begin{tabular}{|c|c|c|c|c|c|c|}
\hline Author & Subjects & Methods & Medication (n) & Control (n) & Duration & Result \\
\hline \multicolumn{7}{|l|}{ GLP-1 related drug } \\
\hline Tesauro $\mathrm{M}$ et al. (50) & MetS & SPG & GLP-1 (5) & Saline & $30 \mathrm{~min}$ & Improved (conditional) \\
\hline Basu A et al. (51) & T2DM & SPG & GLP-1 & Placebo & $240 \mathrm{~min}$ & Improved \\
\hline NystromT et al. (52) & T2DM & FMD & GLP-1 & Saline & $115 \mathrm{~min}$ & Improved \\
\hline Koska J et al. (53) & T2DM & RH-PAT & Exendin-4 & Saline & $210 \mathrm{~min}$ & Improved \\
\hline Ceriello A et al. (54) & T2DM & FMD & GLP-1 (12) & Saline (12) & $2 \mathrm{~h}$ & Improved \\
\hline Irace C et al. (55) & T2DM & FMD & Exendin-4 (10) & Glimepiride (10) & $16 w$ & Improved \\
\hline Ha SJ et al. (56) & Volunteer & FMD & Exenatide (20) & Placebo (20) & $30 \mathrm{~min}$ & Improved \\
\hline Kelly AS et al. (57) & IGT & PAT & Exendin-4 & Metformin & $6 m$ & No change \\
\hline Hopkins ND et al. (58) & ObeseT2DM & FMD & $\begin{array}{l}\text { Exendin- } 4(n=9) \\
\text { Liragrutide }(n=2)\end{array}$ & None $(0)$ & $6 m$ & No change \\
\hline Nomoto $\mathrm{H}$ et al. (59) & T2DM & FMD & Liraglitide (16) & Glargine (15) & $14 w$ & No change \\
\hline \multicolumn{7}{|l|}{ DPP-4 inhibitor } \\
\hline Ayaori $\mathrm{M}$ et al. (60) & T2DM & FMD & $\begin{array}{l}\text { Sitagliptin (66) } \\
\text { Alogliptin (42) }\end{array}$ & Voglibose (24) & $6 w$ & Worsened \\
\hline Maruhashi T et al. (61) & T2DM & FMD & Sitagliptin (17) & $\begin{array}{l}\text { Conventional } \\
\text { therapy (18) }\end{array}$ & $2 y$ & No change \\
\hline Ida S et al. (62) & T2DM & FMD & Trelagliptin (27) & None (0) & $12 w$ & No change \\
\hline Kubota $Y$ et al. (63) & T2DM & FMD & Sitagliptin (40) & None $(0)$ & $12 w$ & Improved \\
\hline Noda Y et al. (64) & $\begin{array}{l}\text { Healthy } \\
\text { volunteer }\end{array}$ & FMD & Alogliptin & Placebo & $1 w$ & Improved \\
\hline van Poppel PC et al. (65) & T2DM & SPG & Vildagliptin & Acarbose & $4 w$ & Improved \\
\hline Nakamura $\mathrm{K}$ et al. (66) & T2DM & FMD & Sitagliptin (31) & Voglibose (35) & $12 w$ & Improved (in both groups) \\
\hline Hashikata T et al. (67) & T2DM & RH-PAT & Tenegliptin (31) & None $(0)$ & $3 m$ & $\begin{array}{l}\text { No difference between two groups } \\
\text { Improved }\end{array}$ \\
\hline
\end{tabular}

MetS, metabolic syndrome; T2DM, type 2 diabetes mellitus; IGT, impaired glucose tolerance; SPG, strain-gauge plethysmography; GLP-1, glucagon-like peptide-1; FMD, flow-mediated dilatation; RH-PAT, reactive hyperemia peripheral arterial tonometry

$1 \mathrm{R}$, increased the eNOS level, and reduced ICAM-1 expression in the aortic endothelium in mice ${ }^{41}$. Liraglutide also inhibited the progression of atherosclerotic plaques, and improved plaque stability in $\mathrm{ApoE}^{-1-}$ mice, although the extent of endothelial vasodilation induced by $\mathrm{ACh}$ was unchanged ${ }^{47}$. Sitagliptin protected the endothelial function of the renal artery in spontaneously hypertensive rats, and exenatide ameliorated endothelial dysfunction in renal arteries from hypertensive patients in an ex vivo study ${ }^{48}$. However, it has been reported that triglyceride-induced endothelial dysfunction was not restored by exendin-4 from rat conduit arteries in ex vivo ${ }^{49)}$.

\section{Clinical data}

Table 2 lists the effects of GLP-1 and GLP-1-related drugs on endothelial function. GLP-1 treatment enhanced endothelium-dependent and endothelium-independent responses to $\mathrm{ACh}$ and sodium nitroprusside (SNP) during infusion of insulin in patients with metabolic syndrome by SPG; ${ }^{.0)}$ several studies have indicated that GLP-1 analogues improved endothelial function ${ }^{51-56)}$. However, Kelly et al. demonstrated that exendin-4 did not improve the responses of RH-PAT compared to metformin in patients with impaired glucose tolerance ${ }^{57)}$. In addition, exendin-4 and liraglutide did not improve the FMD responses in patients with $\mathrm{T} 2 \mathrm{DM}^{58,59}$. Surprisingly, Ayaori et al. reported that sitagliptin and alogliptin led to a deterioration in the FMD response in patients with $\mathrm{T}_{2} \mathrm{DM}^{60)}$. Two papers reported that sitagliptin and trelagliptin did not improve FMD or RH-PAT responses in patients with $\mathrm{T} 2 \mathrm{DM}$ when given for three months ${ }^{61,62)}$. However, sitagliptin, alogliptin, vildagliptin, and tenegliptin improved endothelial dysfunction in most studies $^{63-67)}$. We reported that long-term therapy with sitagliptin failed to improve FMD relative to conventional treatment $t^{61)}$. Adding sitagliptin to conventional antihyperglycemic drugs for two years in patients with T2DM did not alter endothelial function measured by FMD. Antihyperglycemic agents including metformin, pioglitazone, and an $\alpha$-glucosidase inhibitor have been found to improve glycemic control in patients with $\mathrm{T}_{2} \mathrm{DM}^{61,66,68-70)}$. Based on lowering glucose levels with anti-diabetic drugs, reduction of hyperglycemia may improve endothelial dysfunction clinically. DPP-4 inhibitors may also improve endothelial dysfunction, but possibly not more than conventional agents.

It is generally accepted that correcting blood sugar may improve endothelial dysfunction in T2DM. However, its effectiveness beyond the glycemic control is still debated as all studies included fewer than 50 patients, and some of the trials were non-randomized. Therefore, a carefully designed large randomized trial will be required to clearly define the impact of these agents on endothelial function.

\subsection{SGLT2 inhibitors and endothelial function}

\section{Preclinical studies}

New anti-diabetic agents target sodium-glucose cotransporter 2 (SGLT2), the main glucose transporter in the kid- 
ney, which is located in the S1 and S2 segments of the proximal tubule and responsible for reabsorption of $>90 \%$ of glucose in primary urine. SGLT2 inhibitors lower blood glucose by inhibiting the reabsorption of filtered glucose, thereby increasing urinary glucose excretion, which is independent of insulin secretion and action ${ }^{71}$. Generally, SGLT2 inhibitors achieve an emission of 60-100 g/day glucose into urine, equivalent to a caloric loss of $240-400 \mathrm{kcal} / \mathrm{day}$, which can ameliorate systemic glucotoxicity and insulin resistance $^{72}$. In addition to the glycemic pathway, SGLT2 inhibitors are associated with non-glycemic effects, including hemodynamic, metabolic, renal, and neurohormonal effects that decrease blood pressure, weight, visceral adiposity, hyperinsulinemia, arterial stiffness, albuminuria, serum uric acid levels, and oxidative stress ${ }^{73)}$.

SGLT2 inhibitors increase urinary glucose excretion and reduce the serum glucose level through energy loss, and can lead to improved metabolism throughout the body. There are few data on pharmacological cardiovascular effects in vitro. Empagliflozin reduced atherosclerosis in vivo by decreasing inflammation and insulin resistance in $\mathrm{ApoE}^{-1-}$ mice $^{74)}$. Canagliflozin attenuated obesity-induced inflammation in mice ${ }^{75)}$. Ipragliflozin ameliorated impaired phosphorylation of Akt and eNOS, reduced ROS generation, monocyte chemotactic protein (MCP)-1, VCAM-1 and ICAM-1, and ameliorated endothelial dysfunction in diabetic mice ${ }^{76)}$. Oelze et al. reported that empagliflozin improved endothelium-dependent relaxation in diabetic rats $^{77}$. Thus, on the basis of experimental data, SGLT2 inhibitors may ameliorate endothelial dysfunction through the correction of glucose and other metabolic abnormalities.

\section{Clinical study}

Currently, the SGLT2 inhibitors including canagliflozin, dapagliflozin, empagliflozin, ipragliflozin, luseogliflozin, and tofogliflozin are available clinically in Japan. Recently, the EMPA-REG OUTCOME trial showed that empagliflozin greatly improved clinical outcomes in diabetic patients with a high risk of $\mathrm{CV}^{78)}$. Therefore, it may be possible to determine whether other SGLT2 inhibitors can also improve endothelial function. However, there are no pertinent clinical data currently available regarding endothelial function and we are planning to undertake such studies. The results of our studies will be available in 2018 .

\section{Limitations}

Our study has a limitation. It is a comprehensive review and not a systematic review according to PRISMA guidelines.

\section{Conclusions}

Vascular failure and subsequent cardiovascular disease are often fatal, and early prevention of cardiovascular complications by ensuring strict glucose control is essential in pa- tients with T2DM. The current findings add to a growing body of evidence that we might be entering a new era of cardiovascular diabetology with new anti-diabetic drugs. On the other hand, several studies contradicted the beneficial effects on the vasculature of incretin-related agents. For the time being, a definite relationship between treatment with gliptin or gliflozins and endothelial function remains uncertain and needs to be proven. Future large-scale clinical studies and their sub-analyses will provide evidence on whether treatment with gliptins or gliflozins provides clinical benefits for vascular protection beyond glycemic control in patients with T2DM at increased risk of cardiovascular disease.

\section{Conflicts of Interest}

JO has no conflicts of interest regarding the content of the manuscript. $\mathrm{KN}$ has received honorariums from Boehringer Ingelheim, Daiichi Sankyo, Astellas, MSD, Takeda, Mitsubishi Tanabe, and Sanofi; research grants from Sanwa Kagaku Kenkyusho, Astellas, Takeda, Boehringer Ingelheim, Bayer, Teijin, and Mitsubishi Tanabe.

\section{References}

1. Vanhoutte PM. Endothelial dysfunction: the first step toward coronary arteriosclerosis. Circ J 2009; 73: 595-601.

2. Woodman RJ, Chew GT, Watts GF. Mechanisms, significance and treatment of vascular dysfunction in type 2 diabetes mellitus: focus on lipid-regulating therapy. Drugs 2005; 65: 31-74.

3. Esper R, Nordaby R, Vilarino J, Paragano A, Cacharron J, Machado R. Endothelial dysfunction: a comprehensive appraisal. Cardiovas Diabetol 2006; 5: 4.

4. Widlansky ME, Gokce N, Keaney JF Jr, Vita JA. The clinical implications of endothelial dysfunction. J Am Coll Cardiol 2003; 42: 1149-60.

5. Vita JA, Keaney JF. Endothelial function: a barometer for cardiovascular risk? Circulation 2002; 106: 640-2.

6. Higashi Y, Noma K, Yoshizumi M, Kihara Y. Endothelial function and oxidative stress in cardiovascular diseases. Circ J 2009; 73: 411-8.

7. Levine AB, Punihaole D, Levine TB. Characterization of the role of nitric oxide and its clinical applications. Cardiology 2012; 122 : 55-68.

8. Russo G, Leopold JA, Loscalzo J. Vasoactive substances: nitric oxide and endothelial dysfunction in atherosclerosis. Vascul Pharmacol 2002; 38: 259-69.

9. Vásquez-Vivar J, Kalyanaraman B, Martásek P. The role of tetrahydrobiopterin in superoxide generation from eNOS: enzymology and physiological implications. Free Radic Res 2003; 37: 121-7.

10. Vásquez-Vivar J, Martásek P, Whitsett J, Joseph J, Kalyanaraman B. The ratio between tetrahydrobiopterin and oxidized tetrahydrobiopterin analogues controls superoxide release from endothelial nitric oxide synthase: an EPR spin trapping study. Biochem J 2002; 362: 733-9.

11. Chew GT, Watts GF. Coenzyme Q10 and diabetic endotheliopathy: oxidative stress and the 'recoupling hypothesis'. QJM 2004; 97: 537-48.

12. Alp NJ, Channon KM. Regulation of endothelial nitric oxide synthase by tetrahydrobiopterin in vascular disease. Arterioscler Thromb Vasc Biol 2004; 24: 413-20.

13. Widlansky ME, Gutterman DD. Regulation of endothelial function by mitochondrial reactive oxygen species. Antioxid Redox Signal 2011; 15: 1517-30. 
14. Parenti A, Paccosi S, Cairo F, Defraia E. Treatment of periodontitis for the prevention of endothelial dysfunction: a narrative review. Curr Vasc Pharmacol 2015; 13: 749-58.

15. Adela R, Banerjee SK. GDF-15 as a target and biomarker for diabetes and cardiovascular diseases: a translational prospective. J Diabetes Res 2015; 2015: 490842.

16. Ivanova EA, Parolari A, Myasoedova V, Melnichenko AA, Bobryshev YV, Orekhov AN. Peroxisome proliferator-activated receptor (PPAR) gamma in cardiovascular disorders and cardiovascular surgery. J Cardiol 2015; 66: 271-8.

17. Lei J, Vodovotz Y, Tzeng E, Billiar TR. Nitric oxide, a protective molecule in the cardiovascular system. Nitric Oxide 2013; 35: 175-85.

18. Inoue T, Node K. Vascular failure: a new clinical entity for vascular disease. J Hypertens 2006; 24: 2121-30.

19. Oyama J, Satoh S, Suematsu N, Kadokami T, Maeda T, Sugano $\mathrm{M}$, et al. Scavenging free radicals improves endothelial dysfunction in human coronary arteries in vivo. Heart Vessels 2010; 25: 379-85

20. Higashi Y, Sasaki S, Nakagawa K, Matsuura H, Kajiyama G, Oshima T. A noninvasive measurement of reactive hyperemia that can be used to assess resistance artery endothelial function in humans. Am J Cardiol 2001; 87: 121-5.

21. Oyama J, Maeda T, Kouzuma K, Ochiai R, Tokimitsu I, Higuchi $\mathrm{Y}$, et al. Green tea catechins improve human forearm endothelial dysfunction and have antiatherosclerotic effects in smokers. Circ J 2010; 74: 578-88.

22. Widlansky ME, Gokce N, Keaney JF Jr, Vita JA. The clinical implications of endothelial dysfunction. J Am Coll Cardiol 2003; 42: 1149-60.

23. Corretti MC, Anderson TJ, Benjamin EJ, Celermajer D, Charbonneau F, Creager MA, et al. Guidelines for the ultrasound assessment of endothelial-dependent flow-mediated vasodilation of the brachial artery: a report of the International Brachial Artery Reactivity Task Force. J Am Coll Cardiol 2002; 39: 257-65.

24. Rubinshtein R, Kuvin JT, Soffler M, Lennon R, Lavi S, Nelson R, et al. Assessment of endothelial function by non-invasive peripheral arterial tonometry predicts late cardiovascular adverse events. Euro Heart J 2010; 31: 1142-8.

25. Fitch KV, Stavrou E, Looby SE, Hemphill L, Jaff MR, Grinspoon SK. Associations of cardiovascular risk factors with two surrogate markers of subclinical atherosclerosis: endothelial function and carotid intima media thickness. Atherosclerosis 2011; 217: 437-40.

26. Kuvin JT, Patel AR, Sliney KA, Pandian NG, Sheffy J, Schnall $\mathrm{RP}$, et al. Assessment of peripheral vascular endothelial function with finger arterial pulse wave amplitude. Am Heart J 2003; 146 : 168-74.

27. Matsuzawa Y, Sugiyama S, Sumida H, Sugamura K, Nozaki T, Ohba K, et al. Peripheral endothelial function and cardiovascular events in high-risk patients. J Am Heart Assoc 2013; 2: e000426.

28. Green DJ, Jones H, Thijssen D, Cable NT, Atkinson G. Flowmediated dilation and cardiovascular event prediction: does nitric oxide matter? Hypertension 2011; 57: 363-9.

29. McVeigh GE, Brennan GM, Johnston GD, McDermott BJ, McGrath LT, Henry WR, et al. Impaired endothelium-dependent and independent vasodilation in patients with type 2 (non-insulin dependent) diabetes mellitus. Diabetologia 1992; 35: 771-6.

30. Liu H, Hu Y, Simpson RW, Dear AE. Glucagon-like peptide-1 attenuates tumour necrosis factor-alpha-mediated induction of plasminogen activator inhibitor-1 expression. J Endocrinol 2008; 196 : 57-65.

31. Ishibashi $Y$, Matsui $T$, Takeuchi M, Yamagishi S. Glucagon-like peptide-1 (GLP-1) inhibits advanced glycation end product (AGE)induced up-regulation of VCAM-1 mRNA levels in endothelial cells by suppressing AGE receptor (RAGE) expression. Biochem Biophys Res Commun 2010; 391: 1405-8.

32. Oeseburg $H$, de Boer RA, Buikema $H$, van der Harst $P$, van Gilst WH, Silljé HH. Glucagon-like peptide 1 prevents reactive oxygen species-induced endothelial cell senescence through the activation of protein kinase A. Arterioscler Thromb Vasc Biol 2010; 30: 1407-14.

33. Ding L, Zhang J. Glucagon-like peptide-1 activates endothelial nitric oxide synthase in human umbilical vein endothelial cells. Acta Pharmacol Sin 2012; 33: 75-81.

34. Wang D, Luo P, Wang Y, Li W, Wang C, Sun D, et al. Glucagonlike peptide-1 protects against cardiac microvascular injury in diabetes via a cAMP/PKA/Rho-dependent mechanism. Diabetes 2013; 62: 1697-708.

35. Aronis KN, Chamberland JP, Mantzoros CS. GLP-1 promotes angiogenesis in human endothelial cells in a dose-dependent manner, through the Akt, Src and PKC pathways. Metabolism 2013; 62: 1279-86.

36. Liu FQ, Zhang XL, Gong L, Wang XP, Wang J, Hou XG, et al. Glucagon-like peptide 1 protects microvascular endothelial cells by inactivating the PARP-1/iNOS/NO pathway. Mol Cell Endocrinol 2011; 339: 25-33.

37. Xiao-Yun X, Zhao-Hui M, Ke C, Hong-Hui H, Yan-Hong X. Glucagon-like peptide-1 improves proliferation and differentiation of endothelial progenitor cells via upregulating VEGF generation. Med Sci Monit 2011; 17: BR35-41.

38. Erdogdu O, Nathanson D, Sjöholm A, Nyström T, Zhang Q. Exendin-4 stimulates proliferation of human coronary artery endothelial cells through eNOS-, PKA- and PI3K/Akt-dependent pathways and requires GLP-1 receptor. Mol Cell Endocrinol 2010; 325: 26-35

39. Erdogdu O, Eriksson L, Xu H, Sjöholm A, Zhang Q, Nyström T. Exendin-4 protects endothelial cells from lipoapoptosis by PKA, PI3K, eNOS, p38 MAPK, and JNK pathways. J Mol Endocrinol 2013; 50: 229-41.

40. Schisano B, Harte AL, Lois K, Saravanan P, Al-Daghri N, AlAttas O, et al. GLP-1 analogue, Liraglutide protects human umbilical vein endothelial cells against high glucose induced endoplasmic reticulum stress. Regul Pept 2012; 174: 46-52.

41. Gaspari T, Liu H, Welungoda I, Hu Y, Widdop RE, Knudsen LB, et al. A GLP-1 receptor agonist liraglutide inhibits endothelial cell dysfunction and vascular adhesion molecule expression in an ApoE-/- mouse model. Diab Vasc Dis Res 2011; 8: 117-24.

42. Shiraki A, Oyama J, Komoda H, Asaka M, Komatsu A, Sakuma $\mathrm{M}$, et al. The glucagon-like peptide 1 analog liraglutide reduces TNF- $\alpha$-induced oxidative stress and inflammation in endothelial cells. Atherosclerosis 2012; 221: 375-82.

43. Ishibashi Y, Matsui T, Takeuchi M, Yamagishi S. Sitagliptin augments protective effects of GLP-1 against advanced glycation end product receptor axis in endothelial cells. Horm Metab Res 2011; 43: 731-4.

44. Shah Z, Pineda C, Kampfrath T, Maiseyeu A, Ying Z, Racoma I, et al. Acute DPP-4 inhibition modulates vascular tone through GLP-1 independent pathways. Vascul Pharmacol 2011; 55: 2-9.

45. Han L, Yu Y, Sun X, Wang B. Exendin-4 directly improves endothelial dysfunction in isolated aortas from obese rats through the cAMP or AMPK-eNOS pathways. Diabetes Res Clin Pract 2012; 97: 453-60.

46. Arakawa M, Mita T, Azuma K, Ebato C, Goto H, Nomiyama T, et al. Inhibition of monocyte adhesion to endothelial cells and attenuation of atherosclerotic lesion by a glucagon-like peptide-1 receptor agonist, exendin-4. Diabetes 2010; 59: 1030-7.

47. Gaspari T, Welungoda I, Widdop RE, Simpson RW, Dear AE. The GLP-1 receptor agonist liraglutide inhibits progression of vascular 
disease via effects on atherogenesis, plaque stability and endothelial function in an ApoE-/- mouse model. Diab Vasc Dis Res 2013; 10: 353-60.

48. Liu L, Liu J, Wong WT, Tian XY, Lau CW, Wang YX, et al. Dipeptidyl peptidase 4 inhibitor sitagliptin protects endothelial function in hypertension through a glucagon-like peptide 1dependent mechanism. Hypertension 2012; 60: 833-41.

49. Nathanson D, Erdogdu O, Pernow J, Zhang Q, Nyström T. Endothelial dysfunction induced by triglycerides is not restored by exenatide in rat conduit arteries ex vivo. Regul Pept 2009; 157: 813.

50. Tesauro M, Schinzari F, Adamo A, Rovella V, Martini F, Mores N, et al. Effects of GLP-1 on forearm vasodilator function and glucose disposal during hyperinsulinemia in the metabolic syndrome. Diabetes Care 2013; 36: 683-9.

51. Basu A, Charkoudian N, Schrage W, Rizza RA, Basu R, Joyner MJ. Beneficial effects of GLP-1 on endothelial function in humans: dampening by glyburide but not by glimepiride. Am J Physiol Endocrinol Metab 2007; 293: E1289-95.

52. Nyström T, Gutniak MK, Zhang Q, Zhang F, Holst JJ, Ahrén B, et al. Effects of glucagon-like peptide-1 on endothelial function in type 2 diabetes patients with stable coronary artery disease. Am J Physiol Endocrinol Metab 2004; 287: E1209-15.

53. Koska J, Schwartz EA, Mullin MP, Schwenke DC, Reaven PD. Improvement of postprandial endothelial function after a single dose of exenatide in individuals with impaired glucose tolerance and recent-onset type 2 diabetes. Diabetes Care 2010; 33: 102830 .

54. Ceriello A, Esposito K, Testa R, Bonfigli AR, Marra M, Giugliano D. The possible protective role of glucagon-like peptide 1 on endothelium during the meal and evidence for an "endothelial resistance" to glucagon-like peptide 1 in diabetes. Diabetes Care 2011; 34: 697-702.

55. Irace C, De Luca S, Shehaj E, Carallo C, Loprete A, Scavelli F, et al. Exenatide improves endothelial function assessed by flow mediated dilation technique in subjects with type 2 diabetes: results from an observational research. Diab Vasc Dis Res 2013; 10: 72-7.

56. Ha SJ, Kim W, Woo JS, Kim JB, Kim SJ, Kim WS, et al. Preventive effects of exenatide on endothelial dysfunction induced by ischemia-reperfusion injury via KATP channels. Arterioscler Thromb Vasc Biol 2012; 32: 474-80.

57. Kelly AS, Bergenstal RM, Gonzalez-Campoy JM, Bank AJ, Katz H. Effects of exenatide vs. metformin on endothelial function in obese patients with pre-diabetes: a randomized trial. Cardiovasc Diabetol 2012; 11: 64 .

58. Hopkins ND, Cuthbertson DJ, Kemp GJ, Pugh C, Green DJ, Cable NT, et al. Effects of 6 months glucagon-like peptide-1 receptor agonist treatment on endothelial function in type 2 diabetes mellitus patients. Diabetes Obes Metab 2013; 15: 770-3.

59. Nomoto H, Miyoshi H, Furumoto T, Oba K, Tsutsui H, Miyoshi A, et al. A Comparison of the Effects of the GLP-1 Analogue liraglutide and insulin glargine on endothelial function and metabolic parameters: a randomized, controlled trial sapporo atheroincretin study 2 (SAIS2). PLoS One 2015; 10: e0135854.

60. Ayaori M, Iwakami N, Uto-Kondo H, Sato H, Sasaki M, Komatsu $\mathrm{T}$, et al. Dipeptidyl peptidase-4 inhibitors attenuate endothelial function as evaluated by flow-mediated vasodilatation in type 2 diabetic patients. J Am Heart Assoc 2013; 2: e003277.

61. Maruhashi T, Higashi Y, Kihara Y, Yamada H, Sata M, Ueda S, et al. Long-term effect of sitagliptin on endothelial function in type 2 diabetes: a sub-analysis of the PROLOGUE study. Cardiovasc Diabetol 2016; 15: 134.

62. Ida S, Murata K, Betou K, Kobayashi C, Ishihara Y, Imataka K, et al. Effect of trelagliptin on vascular endothelial functions and serum adiponectin level in patients with type 2 diabetes: a preliminary single-arm prospective pilot study. Cardiovasc Diabetol 2016; 15: 153.

63. Kubota Y, Miyamoto M, Takagi G, Ikeda T, Kirinoki-Ichikawa S, Tanaka K, et al. The dipeptidyl peptidase-4 inhibitor sitagliptin improves vascular endothelial function in type 2 diabetes. J Korean Med Sci 2012; 27: 1364-70.

64. Noda Y, Miyoshi T, Oe H, Ohno Y, Nakamura K, Toh N, et al. Alogliptin ameliorates postprandial lipemia and postprandial endothelial dysfunction in non- diabetic subjects: a preliminary report. Cardiovasc Diabetol 2013; 12: 8.

65. van Poppel PC, Netea MG, Smits P, Tack CJ. Vildagliptin improves endothelium-dependent vasodilatation in type 2 diabetes. Diabetes Care 2011; 34: 2072-7.

66. Nakamura K, Oe H, Kihara H, Shimada K, Fukuda S, Watanabe $\mathrm{K}$, et al. DPP-4 inhibitor and alpha-glucosidase inhibitor equally improve endothelial function in patients with type 2 diabetes: EDGE study. Cardiovasc Diabetol 2014; 13: 110.

67. Hashikata T, Yamaoka-Tojo M, Kakizaki R, Nemoto T, Fujiyoshi $\mathrm{K}$, Namba S, et al. Teneligliptin improves left ventricular diastolic function and endothelial function in patients with diabetes. Heart Vessels 2016; 31: 1303-10.

68. Wu S, Li X, Zhang H. Effects of metformin on endothelial function in type 2 diabetes. Exp Ther Med 2014; 7: 1349-53.

69. Hidaka T, Nakagawa K, Goto C, Soga J, Fujii Y, Hata T, et al. Pioglitazone improves endothelium-dependent vasodilation in hypertensive patients with impaired glucose tolerance in part through a decrease in oxidative stress. Atherosclerosis 2010; 210: 521-4.

70. Kato $T$, Inoue $T$, Node $K$. Postprandial endothelial dysfunction in subjects with new-onset type 2 diabetes: an acarbose and nateglinide comparative study. Cardiovasc Diabetol 2010; 9: 12.

71. Chao EC, Henry RR. SGLT2 inhibition--a novel strategy for diabetes treatment. Nat Rev Drug Discov 2010; 9: 551-9.

72. Abdul-Ghani MA, Norton L, Defronzo RA. Role of sodiumglucose cotransporter 2 (SGLT 2) inhibitors in the treatment of type 2 diabetes. Endocrine Rev 2011; 32: 515-31.

73. Ghosh RK, Bandyopadhyay D, Hajra A, Biswas M, Gupta A. Cardiovascular outcomes of sodium-glucose cotransporter 2 inhibitors: a comprehensive review of clinical and preclinical studies. Int $\mathbf{J}$ Cardiol 2016; 212: 29-36.

74. Han JH, Oh TJ, Lee G, Maeng HJ, Lee DH, Kim KM, et al. The beneficial effects of empagliflozin, an SGLT2 inhibitor, on atherosclerosis in ApoE-/- mice fed a western diet. Diabetologia 2017; 60: 364-76.

75. Naznin F, Sakoda H, Okada T, Tsubouchi H, Waise TM, Arakawa $\mathrm{K}$, et al. Canagliflozin, a sodium glucose cotransporter 2 inhibitor, attenuates obesity-induced inflammation in the nodose ganglion, hypothalamus, and skeletal muscle of mice. Eur J Pharmacol 2017; 794: 37-44.

76. Salim HM, Fukuda D, Yagi S, Soeki T, Shimabukuro M, Sata M. Glycemic control with ipragliflozin, a novel selective SGLT2 inhibitor, ameliorated endothelial dysfunction in streptozotocininduced diabetic mouse. Front Cardiovasc Med 2016; 3: 43.

77. Oelze M, Kröller-Schön S, Welschof P, Jansen T, Hausding M, Mikhed Y, et al. The sodium-glucose co-transporter 2 inhibitor empagliflozin improves diabetes-induced vascular dysfunction in the streptozotocin diabetes rat model by interfering with oxidative stress and glucotoxicity. PLoS One 2014; 9: e112394.

78. Zinman B, Wanner C, Lachin JM, Fitchett D, Bluhmki E, Hantel $\mathrm{S}$, et al. EMPA-REG OUTCOME investigators. empagliflozin, cardiovascular outcomes, and mortality in type 2 diabetes. $\mathrm{N}$ Engl $\mathrm{J}$ Med 2015; 373: 2117-28. 